\title{
Cognitive status of patients judged fit for discharge from the post-anaesthesia care unit after general anaesthesia: a randomized comparison between desflurane and propofol
}

Cyrille Robert ${ }^{1}$, Anne Soulier ${ }^{2}$, Didier Sciard ${ }^{3}$, Guillaume Dufour ${ }^{3}$, Corinne Alberti ${ }^{4}$, Priscilla Boizeau ${ }^{4}$ and $^{3}$ Marc Beaussier ${ }^{3 *}$

\begin{abstract}
Background: The Aldrete's score is used to determine when a patient can safely leave the Post-Anaesthesia Care Unit (PACU) and be transferred to the surgical ward. The Aldrete score is based on the evaluation of vital signs and consciousness. Cognitive functions according to the anaesthetic strategy at the time the patient is judged fit for discharge from the PACU (Aldrete's score $\geq 9$ ) have not been previously studied. The aim of this trial was to assess the cognitive status of inpatients emerging either from desflurane or propofol anaesthesia, at the time of PACU discharge (Aldrete score $\geq 9$ ).

Methods: Sixty adult patients scheduled for hip or knee arthroplasty under general anaesthesia were randomly allocated to receive either desflurane or propofol anaesthesia. Patients were evaluated the day before surgery using Digit Symbol Substitution Test (DSST), Stroop Color Test and Verbal Learning Test. After surgery, the Aldrete score was checked every 5 min until reaching a score $\geq 9$. At this time, the same battery of cognitive tests was applied. Each test was evaluated separately. Cognitive status was reported using a combined $Z$ score pooling together the results of all 3 cognitive tests.

Results: Among the 3 tests, only DSST was significantly reduced at Aldrete Score $\geq 9$ in the Desflurane group. Combined Z-scores at Aldrete Score $\geq 9$ were (in medians [interquartils]): $-0.2[-1.2 ;+0.6]$ and $-0.4[-1.1 ;+0.4]$ for desflurane and propofol groups respectively $(P=0.62)$. Cognitive dysfunction at Aldrete score $\geq 9$ was observed in 3 patients in the Propofol group and in 2 patients in the Desflurane group) $(P=0.93)$.

(Continued on next page)
\end{abstract}

\footnotetext{
*Correspondence: marc.beaussier@imm.fr

${ }^{3}$ Department of Anaesthesia, Institut Mutualiste Montsouris, 42 Boulevard Jourdan, 75014 Paris, France

Full list of author information is available at the end of the article
}

(c) The Author(s). 2021 Open Access This article is licensed under a Creative Commons Attribution 4.0 International License, which permits use, sharing, adaptation, distribution and reproduction in any medium or format, as long as you give appropriate credit to the original author(s) and the source, provide a link to the Creative Commons licence, and indicate if changes were made. The images or other third party material in this article are included in the article's Creative Commons licence, unless indicated otherwise in a credit line to the material. If material is not included in the article's Creative Commons licence and your intended use is not permitted by statutory regulation or exceeds the permitted use, you will need to obtain permission directly from the copyright holder. To view a copy of this licence, visit http://creativecommons.org/licenses/by/4.0/. The Creative Commons Public Domain Dedication waiver (http://creativecommons.org/publicdomain/zero/1.0/) applies to the data made available in this article, unless otherwise stated in a credit line to the data. 


\begin{abstract}
(Continued from previous page)
Conclusion: No difference was observed in cognitive status at Aldrete score $\geq 9$ between desflurane and propofol anaesthesia. Although approximately $10 \%$ of patients still had cognitive dysfunctions, an Aldrete score $\geq 9$ was associated with satisfactory cognitive function recovery in the majority of the patients after lower limb arthroplasty surgery under general anaesthesia.
\end{abstract}

Trial registration: Clinical Trials identifier NTC02036736.

Keywords: Cognitive, Anaesthesia, Desflurane, Propofol, PACU

\section{Background}

Recovery from general anaesthesia is a complex process that can be broken down into several stages [1]. The "immediate wake-up" corresponds to the patient regaining consciousness and stable cardiovascular and respiratory conditions [2]. During this sequence, patients are extensively monitored in the Post Anaesthesia Care Unit (PACU) and supervised by specialized staff. Patients must reach a satisfactory level of recovery before being discharged. At present, the Aldrete score is the most commonly used score allowing patients to be discharged from the PACU and transferred to the hospitalization ward [3]. This score has a maximum of 10 points and it is considered that a score $\geq 9$ allows patients to be discharged from the PACU under satisfactory safety conditions. The level of consciousness is one of the parameters of the Aldrete score. However, the Aldrete score is not tailored to address cognitive status recovery, which corresponds to the reappearance of fine psychomotor skills [4]. Cognitive functions encompass several different clinical features corresponding to distinct pathophysiological mechanisms [4-6].

Until now, cognitive dysfunctions have mainly been studied within a few days after surgery (usually 7 days) [4-6]. The pathogenesis of long-term cognitive dysfunction is multifactorial and relates mostly to neuronal inflammation and some aspects of cerebral vulnerability [4-7], that may even be independent of surgery and anaesthesia [8]. This is in contrast with immediate postoperative cognitive function, which is one of the components of the overall process of anaesthesia recovery, mainly related to the residual effect of anaesthetic agents [9].

Until now, the cognitive status of inpatients with an Aldrete score $\geq 9$ when they leave the PACU to be transferred to the ward had never been reported. However, this parameter is of major importance because satisfactory cognitive recovery can allow patients to perceive and express eventual distress and to react appropriately to environmental stimulations when going back to their room. Furthermore, patients with residual memorization troubles are more prone to forget safety recommendations. Finally, cognitive status is clearly one of the components of patient's satisfaction and global appreciation of the quality of recovery [10], as well as a relevant indicator of quality for the anaesthesia department [11].
It remains totally unknown how cognitive recovery follows the course of the reappearance of vital functions. Because the rate of emergence and immediate recovery differs between anaesthetic agents, and in particular between desflurane and propofol [12, 13], it can be hypothesized that cognitive recovery does not strictly follow the course of immediate recovery. The resumption of cognitive function at a given state of immediate recovery, according to the administered anaesthetic agents, has never been investigated.

The aim of this prospective randomized study was to compare the cognitive status of inpatients without preoperative cognitive impairment, emerging either from desflurane or propofol anaesthesia at the time of PACU discharge (Aldrete score $\geq 9$ ).

\section{Materials and methods}

\section{Ethics and patients}

This is a prospective single-center parallel randomized study conducted in St Antoine University Hospital (Assistance-Publique Hôpitaux de Paris). All methods were carried out in accordance with relevant guidelines and regulations and with CONSORT recommendations [14]. Ethical committee approval for this study (Ethical committee $\left.n^{\circ} 13,887-P 120702\right)$ was provided by the Ethical Committee: CPP (Comite de Protection des Personnes) Ile de France V, 184 rue du Fbg St Antoine, Paris, France (Chaiperson Prof JJ Boffa) on 2 April 2013. The study was registered in ClinicalTrials.gov (Clinical Trials identifier: NCT 02036736).

Patients less than 75 years old, undergoing hip or knee arthroplasty under general anaesthesia were eligible in the study. Patients with preoperative dementia (defined as a Mini Mental State evaluation (MMS) [15] of 24 or less), unable to perform the cognitive tests, or who received preoperative psychotropic agents, as well as obese patients $\left(\mathrm{BMI}>35 \mathrm{~kg} \cdot \mathrm{m}^{-2}\right.$ ), patients with chronic alcoholism or addiction were not included.

Definitive eligibility was decided by the anaesthesiologist in charge of the patient on the pre-anaesthetic visit the day before surgery. The information was given and the consent form was signed at that time. 


\section{Randomization}

The randomization sequence was generated electronically with nQuery (version 6.01). Enrollment was done by clinicians at the operating room. After enrollment, treatment assignment was done with a secure study website (Cleanweb, Telemedicine Technologies, Boulogne- Billancourt, France) after verification of eligibility and consent status. The anaesthesiologist, responsible for enrollment and care at the operating room, was the only one knowing the allocation arm of the treatment. They were not involved in judgment criteria measurement thereafter. Access profiles to the e-CRF have been limited depending on the function of the investigator (evaluator vs anaesthesiologist).

Depending on the randomization, the anaesthesia maintenance was provided either by Desflurane (Group D) or Propofol in TIVA (Total Intravenous Anaesthesia) mode (Group P).

\section{Anaesthetic protocol}

No anxiolytic premedication was given to the patient before surgery. Anaesthetic induction was performed with Propofol + Sufentanil + Atracurium. Patients had standard monitoring including depth of anaesthesia using the Bispectral $\left(\mathrm{BIS}^{\oplus}\right)$ index. Hypothermia was prevented by using warming blankets.

All patients were intubated and ventilated with a mixture of $\mathrm{O}_{2} / \mathrm{N}_{2} \mathrm{O}: 50 / 50 \%$. Fluid loading was achieved with crystalloids and/or colloids depending on requirements.

According to randomization, patients were allocated to receive either Desflurane (Group D) or Propofol (Group P) for anaesthesia maintenance.

- Group D: Desflurane Induction with a bolus of Propofol $2-3 \mathrm{mg} / \mathrm{kg}$ Maintenance with a closed circuit of Desflurane with minimal alveolar concentration adapted to maintain a BIS value between 40 and 60 .

- Group P: Propofol

Target controlled administration of Propofol at 2 and $4 \mu \mathrm{g} / \mathrm{ml}$ to be adjusted to maintain a BIS value between 40 and 60 .

Supplemental boluses of Sufentanil and Atracurium were given as required. At the end of surgery (T0), the patient was transferred to the post-anaesthesia care unit (PACU). Tracheal extubation was carried out when the patient was conscious, with a respiratory rate above $12 . \mathrm{min}^{-1}$, a core temperature $>36^{\circ} \mathrm{C}$, and without residual muscle weakness (residual curarization was assessed with Double-Burst Stimulation and antagonized if necessary).
Post-operative pain intensity at rest was evaluated using the Numerical Rating Scale (NRS) with $0=$ no pain and $10=$ maximal imaginable pain intensity. Postoperative analgesia was multimodal. The use of locoregional techniques for post-operative analgesia was encouraged (nerve block, trunk block $+/$ - placement of a perineural catheter $+/-$ wound infiltration). During the stay in PACU, if NRS $\geq 3$, morphine was administered by titration (bolus of $1 \mathrm{mg}$ IV repeated every $5 \mathrm{~min}$ until NRS at rest $<3)$.

After arrival in the PACU, the Aldrete score was checked every $5 \mathrm{~min}$. Once the score of $\geq 9$ had been attained, the cognitive tests were carried out for a second time.

The data from these tests was collected by the same investigator as the day before surgery in the case report form.

\section{Cognitive assessment}

Preoperatively, the patient's educational status was registered and a measurement of their anxiety level using the Amsterdam Preoperative Anxiety Information Scale [16] was determined.

Cognitive tests were performed by a blinded anaesthesiologist. The same anaesthesiologist made the preoperative and postoperative assessments. Cognitive tests were chosen on the basis of experimental validation and feasibility criteria. Because the process of cognition is multidimensional, it is mandatory to have several different tests exploring multiple distinct components [17, 18]. In this perspective, it was chosen to use, the Digit Symbol Substitution Test (DSST) [19], the Stroop color word interference test [20,21], and the Visual Verbal Learning Test (VLT) [22]. The DSST was derived from the Wechsler adult intelligence scale: On a sheet of paper with a code indicating 9 letters corresponding to 9 digits, the patient must fill out horizontal rows with letters associated with empty cells in $90 \mathrm{~s}$. In the word and colour interference test (Stroop color word interference test): the patient reads a list of words indicating colours (task 1), then gives the name of the colours in a list of colored rectangles (task 2). Finally, the patient must read words indicating one color with the word printed in a different colour (task 3). Patients have $45 \mathrm{~s}$ to complete each task. The number of correct words was counted. The VLT is a memory test that explores the immediate and long-term recall of a list of 10 words. All tests were affected in the same way by cognitive dysfunction.

In accordance with guidelines on how to conduct a multidimensional cognitive evaluation, an overall score that takes into account inter-individual variability and learning effect, in relation to the standard deviation of the population was calculated ( $\mathrm{Z}$ score) [23]. 


$$
\text { Z score }=\frac{X_{0}-\overline{X_{0}}}{\sqrt{\frac{\sum\left(X_{0}-\overline{X_{0}}\right) 2}{n}}}
$$

For any test, the average performance of a population is diminished by the pre-operative control value and divided by the standard deviation for the variation in the population, thereby giving a measurement of the magnitude of the deviation from the reference with appropriate sign. Signs were adjusted to assure that deterioration corresponds to a negative score for all tests.

The Z-scores for all tests can be summarized, calculating a combined Z-score that is calculated as the sum of all Z-scores divided by the standard deviation for the sum Z-scores. In our case, cognitive dysfunction was defined as a combined Z-score $<-2$, or at least $2 \mathrm{Z}$-scores for single test parameters $<-2[23]$.

\section{Criteria of evaluation}

A primary criterion of evaluation was the difference on cognitive status between Desflurane and Propofol at Aldrete's score $\geq 9$. The main judgement criterion was $\mathrm{Z}$ combined scores at the time Aldrete score $\geq 9$.

As secondary criteria, each test was analyzed separately in order to evaluate its sensitivity in screening for post-operative cognitive and psychomotor dysfunction. These analyses were performed using the $\mathrm{Z}$ test for each individual test but also by calculating the difference between pre- and postoperative assessments. Moreover, the number of patients with cognitive deterioration at Aldrete score $\geq 9$ (regardless of the anaesthetic agent), intraoperative parameters, such as sufentanil consumption and BIS value was registered, as well as time interval between end of surgery and tracheal extubation, time interval between tracheal extubation and Aldrete score $\geq$ 9, pain intensity and opiate consumption in PACU. Finally, patient's satisfaction was assessed with a 5 points categorical scale.

\section{Statistical analysis}

Statistical analysis was performed according to published guidelines by the International Study of Postoperative Cognitive Dysfunction (ISPOCD) group [23].

$\mathrm{Z}$ scores between the two groups were compared by a t-test. In each group, Stroop, DSST and VLT scores between D0 and D1 were compared by paired t-tests or conditional logistic regressions when the assumption about symmetric distribution failed. The number of patients having cognitive deterioration at Aldrete score $\geq 9$ according to anaesthetic agents was compared using Chi-2 test with Fisher exact correction.

Calculating the required sample size was complex as it depends on the tests selected and the way in which they are processed. To date, no published works have used the same battery of tests as in our evaluation context. Given the pilot data obtained in our department, the difference in combined Z-score was 1.1. Therefore a total number of 30 patients per group made it possible to highlight a difference of $20 \%$ (i.e. 0.9) in the $\mathrm{Z}$ score with an $\alpha$ risk of $5 \%$ and a $\beta$ risk of $10 \%$. Enrolled patients who did not participate further in the study were excluded for final analysis. Results are presented in medians [interquartils] or mean $\pm \mathrm{SD}$. The threshold for statistical significance was set at $P<0.05$.

\section{Results}

A total of 60 patients was enrolled and randomly allocated to Desflurane $(n=30)$ or Propofol $(n=30)$ subgroups. Five patients were excluded for final analysis in the Desflurane group ( 2 for missing data and 3 for protocol violation), and 3 in the Propofol group (1 for missing data and 2 for protocol violation) (Fig. 1).

Demographic data are presented in Table 1 and did not statistically differ between groups. Intraoperative and postoperative data did not differ between the 2 groups (Table 2). Preoperative Mini Mental State (MMS) was 29 [27-29] and 29 [28-30] respectively in the Desflurane and Propofol groups. Preoperative anxiety, measured using the Amsterdam Preoperative Anxiety and Information Scale (APAIS) was 14 [7-17] and 15 [10-19] respectively in the Desflurane and Propofol groups (no significant difference). Preoperative cognitive functions did not significantly differ between groups (Fig. 2 and Table 3).

Results of the 3 tests at Aldrete score $\geq 9$ are presented in Table 3. Differences between preoperative tests and tests at Aldrete $\geq 9$ are presented in Table 3. Only DSST in the Desflurane group was significantly reduced at Aldrete $\geq 9$ in comparison to preoperative value. Combined Z-scores at Aldrete score $\geq 9$ were $-0.2[-1.2 ;+$ $0.6] \quad(\min =-2.4 ; \quad \max =+2.5) \quad$ and $-0.4 \quad[-1.1 ;+0.4]$ $(\min =-3.0 ; \max =+1.7)$ for the Desflurane and Propofol groups respectively $(P=0.62)$ (Fig. 2$)$. The majority of patients did not present any cognitive dysfunction at Aldrete score $\geq 9$. Only 3 patients in the Propofol group (combined Z-score $=-2.6,-2.8$ and -3.0 ) and 2 patients in the Desflurane group (combined Z-score $=-2.1$ and -2.4 ) had a significant cognitive deterioration at the discharge time from PACU $(P=0.93)$.

Performing these cognitive tests was judged as "easy" or "very easy" for 18 patients in the Desflurane group and 21 patients in the Propofol group $(P=0.93)$.

\section{Discussion}

In this study, it was found that the majority of patients had a satisfactory cognitive recovery at the time the Aldrete score achieved a value $\geq 9$. Only 2 patients in the Desflurane group and 3 patients in the Propofol group 


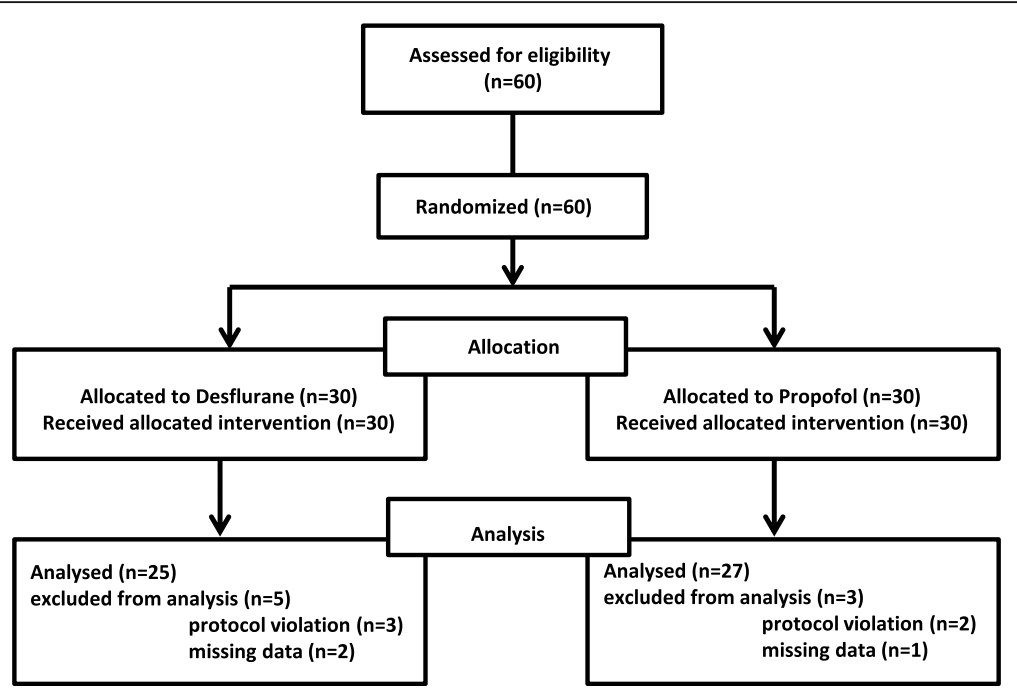

Fig. 1 CONSORT Flow diagram

had significant cognitive dysfunction when they were discharged from PACU. No difference was observed between desflurane and propofol anaesthesia, regardless of the time-interval to reach this score after the end of anaesthesia.

Cognitive recovery after general anaesthesia for lower limb arthroplasty surgery has been the subject of many studies [24, 25]. Regarding this topic, this surgical model is of particular interest because it uses highly reproducible procedures performed on elderly people. Recovery of cognitive function during the immediate postoperative period should be distinguished from cognitive deterioration (confusion or delirium) occurring days or weeks after the surgery and that are ascribed to other mechanisms than the residual effects of anaesthetic drugs [8]. In a previous study, delirium signs were observed in 31\% of the patients $30 \mathrm{~min}$ after the end of the surgery, and were still present in $4 \%$ of them at PACU discharge [26]. In accordance, another report found a $15 \%$ incidence of delirium during the stay in PACU [27]. However, these articles focused more on behaviour (agitated or

Table 1 Demographic data and information on procedures

\begin{tabular}{lll}
\hline & $\begin{array}{l}\text { Desflurane } \\
\boldsymbol{n}=\mathbf{3 0}\end{array}$ & $\begin{array}{l}\text { Propofol } \\
\boldsymbol{n}=\mathbf{3 0}\end{array}$ \\
\hline Age (yrs) & $68[59-74]$ & $70[62-73]$ \\
Sex (M/F) & $10 / 20$ & $11 / 19$ \\
Height $(\mathrm{cm})$ & $165[160-173]$ & $164[157-174]$ \\
Weight $(\mathrm{kg})$ & $77[65-85]$ & $70[62-85]$ \\
BMI $\left(\mathrm{kgg.m}^{-2}\right)$ & $28[23-29]$ & $27[25-29]$ \\
Surgical procedures: & & \\
$\quad$ Hip arthroplasty & 16 & 16 \\
Knee arthroplasty & 14 & 14 \\
\hline
\end{tabular}

Results in medians [interquartils]. No difference between groups hypoactive signs rated on the Richmond Agitation and Sedation Scale) than on strictly cognitive status. The cognitive status at a predetermined level of awakening had never been investigated.

One of the major methodologic issues regarding cognitive assessment is to avoid confounding factors. Among other factors of influence, great attention was paid not to include patients with pre-operative cognitive deterioration [28]. Similarly, because the level of anxiety may interfere with cognitive evaluation, every patient had a pre-operative anxiety measurement.

Evaluation of cognitive function should be conducted according to several methodological recommendations [23]. It is recommended to use different tests exploring different components of cognitive skills. In the present study, it was decided to only use tests previously validated for the study of psychoactive drugs. Therefore we utilized the digit symbol substitution test (DSST) which is considered by psychometricians as a reference test for the evaluation of central coding disorders [17]. Like all coding tests, it explores particularly vulnerable functions in the postoperative period [29] and is able to discriminate recovery rates between different agents [30]. In the current study, DSST was the only test to be significantly impaired at Aldrete's score $\geq 9$. The Stroop color word interference (Stroop test) is an interference test between words and colours [20,21]. This test is particularly robust for its reproducibility, independent of cultural factors, and explores specifically the functions of attention and concentration. The Verbal Learning Test explores the memory function which is very sensitive to the residual effects of halogenated agents as well as propofol $[31,32]$. It should be noted that all these tests were considered easy to carry out by the majority of the patients. 
Table $\mathbf{2}$ Intraoperative and post-operative anaesthetic data

\begin{tabular}{|c|c|c|c|}
\hline & Desflurane & Propofol & $P$ \\
\hline Duration of anaesthesia (min) & $120[98-280]$ & $120[84-320]$ & 0.69 \\
\hline BIS at end of surgery & $48[43-54]$ & $51[41-58]$ & 0.73 \\
\hline Time interval between end of anaesthesia and tracheal extubation (min) & $10[6-15]$ & $10[5-20]$ & 0.45 \\
\hline Time interval between end of anaesthesia and Aldrete score $\geq 9$ & 70 [52-90] & $83[65-110]$ & 0.16 \\
\hline VAS at arrival in PACU (mm) & $50[0-80]$ & $30[0-70]$ & 0.33 \\
\hline Morphine titration in PACU (Yes/No) & $15 / 10$ & $13 / 14$ & 0.39 \\
\hline $\begin{array}{l}\text { Morphine titration in PACU (mg) } \\
\text { (among titrated patients) }\end{array}$ & $10[8-12]$ & $10[9-11]$ & 0.78 \\
\hline PONV in PACU (n) & 2 & 2 & 1 \\
\hline
\end{tabular}

BIS Bispectral Index monitoring, VAS Verbal Analogic Scale, PONV Post-operative Nausea and Vomiting, PACU Post Anaesthesia Care Unit No significant difference between groups

Taking into consideration all of these methodological limitations, it was decided to strictly follow the usual recommendations on cognitive assessment [23]. In particular, the variability of the test measurements was analyzed in relation to the standard deviation of the population using the $\mathrm{Z}$ score. $\mathrm{Z}$ scores of all tests were thereby aggregated into a global "combined $Z$ value".

Cognitive evaluation is part of the global concept of post-operative quality of recovery [1]. As such, cognitive evaluation has usually been assessed at a constant timeinterval after the end of anaesthesia, with $81 \%$ of patients judged as cognitively recovered at $90 \mathrm{~min}$ [33]. However, performing the cognitive evaluation at a constant timeinterval from the end of anaesthesia could introduce some variability related to the different rate of elimination of anaesthetic agents and different conditions of immediate recovery. In this study, a different approach was chosen, allowing us to determine cognitive function at the same state of immediate recovery for every patient, regardless of the anaesthetic agents. It was chosen to search for the differences between desflurane and propofol. Desflurane is characterized by a rapid elimination rate [34]. Propofol is also characterised by fast elimination once administration has ceased. It is usually considered that desflurane allows for a faster recovery than propofol, even after short term exposure [35]. In the current study, no difference on cognitive status was found between desflurane and propofol at Aldrete score $\geq 9$, while this was obtained sooner in the Desflurane group than in the Propofol group (not significantly different). This allows us to conclude that regardless of the anaesthetic agents, cognitive status gives the same level of performance at the same level of immediate recovery assessed by the Aldrete score. This result gives

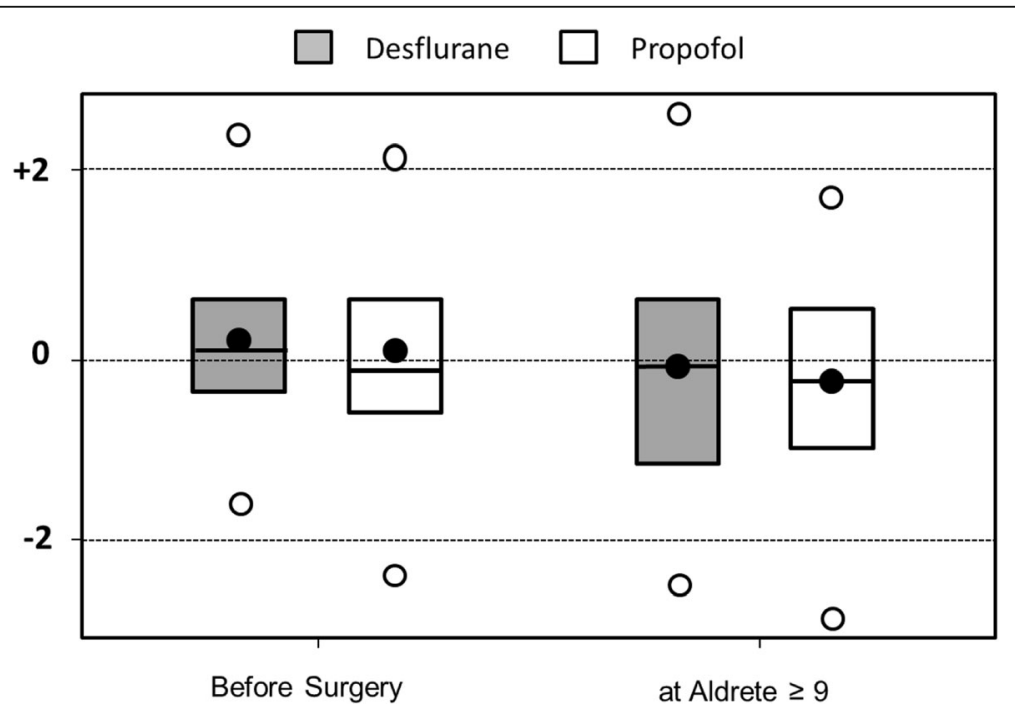

Fig. 2 Evolution of combined Z scores between pre-operative and Aldrete score $\geq 9$ assessments according to anaesthetic agent. Filled circles = means, horizontal lines = medians, box $=$ interquartils, empty circles $=$ extremes. No significant difference between groups 
Table 3 Cognitive functions

\begin{tabular}{|c|c|c|c|c|c|c|c|}
\hline & \multicolumn{3}{|l|}{ Desflurane } & \multicolumn{3}{|l|}{ Propofol } & \multirow[t]{2}{*}{$P *$} \\
\hline & Pre-operative & Aldrete $\geq 9$ & $P$ & Pre-operative & Aldrete $\geq 9$ & $P$ & \\
\hline DSST & $29[24 / 47]$ & $25[19 / 38]$ & & $22[17 / 31]$ & 25 [15/30] & & \\
\hline Mean difference & & $-8[-9 /-1]$ & 0.01 & & $-1[-9 / 9]$ & 0.45 & \\
\hline Z Score DSST & & $-0.4[-0.8 / 0.6]$ & & & $-0.4[-1.1 / 0]$ & & 0.46 \\
\hline Stroop test & 117 [106/128] & $120[102 / 128]$ & & 115 [110/125] & 112 [102/120] & & \\
\hline Mean difference & & $-1[-7 / 0]$ & 0.23 & & $-3[-11 / 2]$ & 0.06 & \\
\hline Z score Stroop test & & $0.4[-1.3 / 1.1]$ & & & $-0.3[-1.3 / 0.4]$ & & 0.37 \\
\hline VLT & $6[3 / 10]$ & $6[5 / 7]$ & & $6[2 / 10]$ & $6[4 / 8]$ & & \\
\hline Mean difference & & $0[-1 / 1]$ & 0.81 & & $0[-1 / 2]$ & 0.76 & \\
\hline Z Score VLT & & $-0.1[-0.6 / 0.4]$ & & & $-0.1[-1.1 / 0.9]$ & & 0.91 \\
\hline
\end{tabular}

Results in medians [interquartils]

DSST Digit Symbol Substitution Test; VLT Verbal Learning Test

* statistical analysis comparing Desflurane and Propofol subgroups

strong credit for the Aldrete score to be used as a means to determine a patient's ability to leave the PACU under satisfactory safety conditions.

This study has some limitations. Cognitive testing very soon after general anaesthesia is somewhat problematic because of numerous confounding factors. In this study, great attention was paid to standardize anaesthesia and pain treatment. However, it cannot be excluded that other external or environmental factors, such as noise in PACU, might have interfered with our results. Regarding pain values, no statistical difference was observed between groups. Because of morphine titration, pain intensity on NRS was $<3$ in every patient leaving the PACU. Similarly, morphine requirement did not differ between groups. It should be noted that morphine by itself has no influence on psychomotor performance in healthy subjects [36]. Potential bias induced by inter-individual variability and learning effects are common in cognitive evaluation. In this current approach, these factors were reduced by the use of $\mathrm{Z}$ score instead of direct average values. The single-center nature of this evaluation, as well as the small sample size, limits the ability to extrapolate the current results to other conditions. Finally, it should be noted that patients included in the final analysis were highly selected. In particular, patients with preoperative dementia or cognitive decline were excluded. In addition, because we wanted to focus on immediate cognitive recovery during awakening, we elected to limit the risk of variability induced by too wide ranges of ages or BMI. It is highly probable that results would have been different in another population.

In conclusion, no difference was observed in cognitive status at Aldrete score $\geq 9$ between desflurane and propofol. Although approximately $10 \%$ of patients still have cognitive dysfunctions, an Aldrete score $\geq 9$ was associated with satisfactory cognitive function recovery in the majority of the patients operated on lower limb arthroplasty surgery under general anaesthesia. This reinforces the clinical value of using Aldrete score to give the ability to be discharged from the PACU after general anaesthesia.

\section{Informed consent}

An information sheet explaining the project and an informed consent sheet have been drafted. All information was explained to the patient, during an interview prior to inclusion, and therefore with an investigator of the project at the time of anaesthesia consultation.

A period of reflection of between 7 and 30 days preoperatively from the anaesthesia consultation was left between the presentation of the study and the signing of the Inform Consent.

The written Inform Consent was obtained from the patient during the preanaesthetic visit the night before the intervention.

\section{Assistance with the article}

The authors want to thank Mr. Paul Bennett for his assistance in English proofreading.

\section{Authors' contributions}

CR: Conceptualization; Data curation; Investigation; Methodology. AS: Data curation; Funding acquisition; Investigation. DS: Conceptualization; Writing review \& editing. GD: Writing - review \& editing. CA / PB: Formal analysis; Statistical assistance. MB: Conceptualization; Project administration; Funding acquisition; Writing - review \& editing. The author(s) read and approved the final manuscript.

\section{Funding}

This study received a grant from Baxter - France SAS. This grant was used to pay for data management and statistical assistance. The study was carried out in total independence and results are the exclusive property of the authors.

Availability of data and materials

Data collected for this study are available at Unit of Clinical Epidemiology, CHU Robert Debré, University Paris Diderot, Sorbonne Paris-Cité. Pr Corinne Alberti listed among the authors.

\section{Declarations}

\section{Ethics approval}

Ethical committee approval for this study (Ethical committee $n^{\circ} 13,887$ -

P120702) was provided by the Ethical Committee: CPP: Comite de Protection 
des Personnes Ile de France V, 184 rue du Fbg St Antoine, Paris, France (Chaiperson Prof JJ Boffa) on 2 April 2013.

The study was registered in ClinicalTrials.gov (Clinical Trials identifier: NTC 02036736).

\section{Consent for publication}

The results were reported in this publication. The ranking of authors is defined depending on the actual contribution of each investigator in recruitment, and the contribution of each member of the leading committee to the design, the conduct of the study and the writing of the article according to rules that were defined at the first investigator meeting. AP-HP owns the data and any use or transfer to a third party can not be made without prior agreement.

\section{Competing interests}

The authors do not declare any conflict of interest in relation with the topic of this study.

\section{Author details}

'Department of Anaesthesia and Critical Care, Clinique Mutualiste de Pessac, Pessac, France. ${ }^{2}$ Department of Anaesthesia and Critical Care, St-Antoine Hospital. Assistance Publique-Hôpitaux de Paris, 75012 Paris, France. ${ }^{3}$ Department of Anaesthesia, Institut Mutualiste Montsouris, 42 Boulevard Jourdan, 75014 Paris, France. ${ }^{4}$ Unit of Clinical Epidemiology, Assistance Publique-Hôpitaux de Paris, CHU Robert Debré, University Paris Diderot, Sorbonne Paris-Cité, CIC-EC 1426 and, UMR-S 1123 ECEVE, 75019 Paris, France.

\section{Received: 20 November 2020 Accepted: 22 February 2021} Published online: 11 March 2021

\section{References}

1. Royse CF, Newman S, Chung F, Stygall J, McKay RE, Boldt J, Servin FS, Hurtado I, Hannallah R, Yu B, Wilkinson DJ. Development and feasibility of a scale to assess postoperative recovery: the post-operative quality recovery scale. Anesthesiology. 2010;113:892-905

2. Whitaker Chair DK, Booth $\mathrm{H}$, Clyburn P, Harrop-Griffiths W, Hosie H, Kilvington B, Macmahon M, Smedley P, Verma R. Association of Anaesthetists of Great Britain and Ireland. Immediate post-anaesthesia recovery 2013: Association of Anaesthetists of Great Britain and Ireland. Anaesthesia. 2013;68:288-97.

3. Aldrete J. The post-anesthesia score revisited. J Clin Anesth. 1995;7:89-91.

4. Evered L, Silbert B, Knopman DS, Scott DA, DeKosky ST, Rasmussen LS, Oh ES, Crosby G, Berger M, Eckenhoff RG, Nomenclature Consensus Working Group. Recommendations for the nomenclature of cognitive change associated with anaesthesia and surgery-2018. Anesthesiology. 2018;129: 872-9.

5. Newman S, Stygall J, Hirani S, Shaefi S, Maze M. Postoperative cognitive dysfunction after noncardiac surgery: a systematic review. Anesthesiology. 2007;106:572-90.

6. Evered LA, Silbert BS. Postoperative cognitive dysfunction and noncardiac surgery. Anesth Analg. 2018;127:496-505.

7. Sanders RD, Pandharipande PP, Davidson AJ, Ma D, Maze M. Anticipating and managing postoperative delirium and cognitive decline in adults. $\mathrm{Br}$ Med J. 2011 Jul 20;343:d4331.

8. Evered L, Scott DA, Silbert B, Maruff P. Postoperative cognitive dysfunction is independent of type of surgery and anesthetic. Anesth Analg. 2011;112: 1179-85.

9. Myles P, Weitkamp B, Jones K, Melick J, Hensen S. Validity and reliability of a postoperative quality of recovery score: the QoR-40. Br J Anaesth. 2000;84:11-5.

10. Macario A, Weinger M, Carney S, Kim A. Which clinical anesthesia outcomes are important to avoid? The perspective of patients. Anesth Analg. 1999;89: 652-8.

11. Fleisher LA. Quality anesthesia: medicine measures, Patients Decide. Anesthesiology. 2018;129:1063-9.

12. Lebenbom-Mansour M, Pandit S, Kothary S, Randel G, Levy L. Desflurane versus propofol anaesthesia: a comparative analysis in outpatients. Anaesth Analg. 1993;76:936-41.

13. Gupta A, Stierer T, Zuckerman R, Sakima N, Parker S, Fleisher L. Comparison of recovery profile after ambulatory anaesthesia with Propofol, Isoflurane, Sevoflurane and Desflurane : a systematic review. Anaesth Analg. 2004;98:632-41.
14. Moher D, Schulz KF, Altman DG, CONSORT GROUP (consolidated standards of reporting trials). The CONSORT statement: revised recommendations for improving the quality of reports of parallel-group randomized trials. Ann Intern Med. 2001;17:657-62.

15. Folstein MF, Folstein SE, McHugh PR. "mini-mental state". A practical method for grading the cognitive state of patients for the clinician. J Psychiatr Res. 1975;12:189-98.

16. Moerman N, van Dam FS, Muller MJ, Oosting H. The Amsterdam preoperative anxiety and information scale (APAIS). Anesth Analg. 1996;82: 445-51.

17. Hindmarch I. Psychomotor function and psychoactive drugs. Br J Clin Pharmacol. 1980;10:189-209.

18. Zuurmond WW, Balk VA, van Dis $H$, van Leeuwen $L$, Paul EA. Multidimensionality of psychological recovery from anesthesia. Analysing six recovery tests. Anaesthesia. 1989:44:889-92.

19. Wechsler $\mathrm{D}$. The measurement of adult intelligence: digit symbol test. Baltimore: The Williams\&Wilkins Company; 1944

20. Houx PJ, Jolles J, Vreeling FW. Stroop interference: aging effects assessed with the Stroop color-word test. Exp Aging Res. 1993;19:209-24.

21. Van der Elst W, Van Boxtel MP, Van Breukelen GJ, Jolles J. The Stroop colorword test: influence of age, sex, and education; and normative data for a large sample across the adult age range. Assessment. 2006;13:62-79.

22. Brand $\mathrm{N}$, Jolles J. Learning and retrieval rate of words presented auditorily and visually. J Gen Psychol. 1985;112:201-10.

23. Rasmussen LS, Larsen K, Houx P, Skovgaard LT, Hanning CD, Moller JT, ISPOCD group. The International Study of Postoperative Cognitive Dysfunction The assessment of postoperative cognitive function. Acta Anaesthesiol Scand. 2001;45:275-89.

24. Weinstein SM, Poultsides L, Baaklini LR, Mörwald EE, Cozowicz C, Saleh JN, Arrington MB, Poeran J, Zubizarreta N, Memtsoudis SG. Postoperative delirium in total knee and hip arthroplasty patients: a study of perioperative modifiable risk factors. Br J Anaesth. 2018;120:999-1008.

25. Konishi Y, Evered LA, Scott DA, Silbert BS. Postoperative cognitive dysfunction after Sevoflurane or Propofol general anaesthesia in combination with spinal anaesthesia for hip arthroplasty. Anaesth Intensive Care. 2018:46:596-600.

26. Card E, Pandharipande P, Tomes C, Lee C, Wood J, Nelson D, Graves A, Shintani A, Ely EW, Hughes C. Emergence from general anaesthesia and evolution of delirium signs in the post-anaesthesia care unit. Br J Anaesth. 2015:115:411-7.

27. Xará D, Silva A, Mendonça J, Abelha F. Inadequate emergence after anesthesia: emergence delirium and hypoactive emergence in the Postanesthesia care unit. J Clin Anesth. 2013:25:439-46.

28. Silbert B, Evered L, Scott DA, McMahon S, Choong P, Ames D, Maruff $P$, Jamrozik K. Preexisting cognitive impairment is associated with postoperative cognitive dysfunction after hip joint replacement surgery. Anesthesiology. 2015;122:1224-34.

29. Silverstein JH, Steinmetz J, Reichenberg A, Harvey PD, Rasmussen LS Postoperative cognitive dysfunction in patients with preoperative cognitive impairment: which domains are most vulnerable? Anesthesiology. 2007;106:431-5.

30. Eshima RW, Maurer A, King T, Lin BK, Heavner JE, Bogetz MS, Kaye AD. A comparison of airway responses during Desflurane and Sevoflurane administration via a laryngeal mask airway for maintenance of anesthesia. Anesth Analg. 2003;96:701-5.

31. Galinkin JL, Janiszewski D, Young CJ, Klafta JM, Klock PA, Coalson DW Apfelbaum JL, Zacny JP. Subjective, psychomotor, cognitive, and analgesic effects of subanesthetic concentrations of Sevoflurane and nitrous oxide. Anesthesiology. 1997:87:1082-8.

32. Zacny JP, Lichtor JL, Coalson DW, Finn RS, Uitvlugt AM, Glosten B, Flemming DC, Apfelbaum JL. Subjective and psychomotor effects of subanesthetic doses of Propofol in healthy volunteers. Anesthesiology. 1992; 76:696-702.

33. Lindqvist $M$, Royse $C$, Brattwall $M$, Warrén-Stomberg M, Jakobsson J. Postoperative quality of recovery scale: the impact of assessment method on cognitive recovery. Acta Anaesthesiol Scand. 2013;5:1308-12.

34. Eger El 2nd, Shafer SL. Tutorial: context-sensitive decrement times for inhaled anaesthetics. Anesth Analg. 2005;101:688-96.

35. Gupta A, Stierer T, Zuckerman R, Sakima N, Parker SD, Fleisher LA. Comparison of recovery profile after ambulatory anesthesia with propofol, isoflurane, Sevoflurane and Desflurane: a systematic review. Anesth Analg. 2004;98:632-41 
36. O'Neill WM, Hanks GW, Simpson P, Fallon MT, Jenkins E, Wesnes K. The cognitive and psychomotor effects of morphine in healthy subjects: a randomized controlled trial of repeated (four) oral doses of

dextropropoxyphene, morphine, lorazepam and placebo. Pain. 2000;85:209-15.

\section{Publisher's Note}

Springer Nature remains neutral with regard to jurisdictional claims in published maps and institutional affiliations.

Ready to submit your research? Choose BMC and benefit from:

- fast, convenient online submission

- thorough peer review by experienced researchers in your field

- rapid publication on acceptance

- support for research data, including large and complex data types

- gold Open Access which fosters wider collaboration and increased citations

- maximum visibility for your research: over $100 \mathrm{M}$ website views per year

At BMC, research is always in progress.

Learn more biomedcentral.com/submissions 